\title{
A dynamic model of electronic wedge brake: experimental, control and optimization
}

\author{
Mohd Hanif Che Hasan', Mohd Khair Hassan², Fauzi Ahmad ${ }^{3}$, Mohammad Hamiruce Marhaban ${ }^{4}$, \\ Sharil Izwan Haris ${ }^{5}$ \\ ${ }^{1,3}$ Faculty of Electrical and Electronic Engineering Technology, Universiti Teknikal Malaysia Melaka (UTeM), Malaysia \\ ${ }^{2,4}$ Faculty of Engineering, Universiti Putra Malaysia (UPM), Malaysia \\ 3,5 Faculty of Mechanical Engineering, Universiti Teknikal Malaysia Melaka (UTeM), Malaysia
}

\begin{abstract}
Article Info
Article history:

Received Apr 23, 2021

Revised May 18, 2021

Accepted May 19, 2021

\section{Keywords:}

Brake-by-wire

Electronic wedge brake

EWB mathematical model

Self energize brake

Wedge brake system

ABSTRACT

This paper discusses the process of modelling and parameter selection for the creation of the electronic wedge brake system (EWB). The system involves a permanent magnet DC engine (PMDC) that drives the motor, the gear leadscrew, and the brake core. The proposed model is simpler and more flexible which can be used in both the most well-known EWB designs either natural or optimized EWB. The selection of the motor is rendered according to the brake specifications. The wedge angle profile is centred on the derivation of EWB system that consists of brake actuator, wedge mechanism dynamic, and wedge characteristic brake factor. Control and optimization are carried out with specific coefficients of friction of the brake pads to maintain operating reliability. A 5th-order brake simulation model of the EWB in a single state-space was derived and a simulation was conducted to verify the distribution of force. The efficiency of the brake clamping force control system was assessed by proportional-integral-derivative (PID) control. The performance of the proposed controller is verified in simulations and experiments using a prototype electronic wedge brake. The research findings indicate, the actuator restriction is deemed to achieve consistent performance against full range braking during the EWB control design.
\end{abstract}

This is an open access article under the CC BY-SA license.

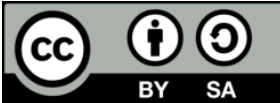

\section{Corresponding Author:}

Mohd Hanif Che Hasan

Faculty of Electrical and Electronic Engineering Technology

Universiti Teknikal Malaysia Melaka

76100 Melaka, Malaysia

Email: hanif.hasan@utem.edu.my

\section{INTRODUCTION}

There is a clear trend in the automotive industry today towards power-by-wire technologies designed to replace hydraulic or pneumatic systems with comparable electrically powered ones. Recently, electronic wedge brake (EWB) received attention for introducing "brake -by -wire" solutions. Various EWB prototypes were first introduced by the German aerospace center (eStop®-GMBH) [1] and are widely reported in the literature review. It begins from a single motor [1] to a double motor [2], [3] and then returns to a single motor [4]-[12] to mechanically minimize the backlash. The optimized EWB version was introduced to increase EWB brake efficiency [8]. To this end, the angle of the engine's actuation during the mechanical design should be set equal to the angle of the coil. To this end, the angle of the engine's actuation during the mechanical design should be set equal to the angle of the wedge. Based on this basis, several attempts have been made by researchers based on this design concept [5], [13]-[18]. 
The findings largely confirm that the use of a wedge in an electromechanical brake mechanism can dramatically reduce the necessary actuating forces and thus allow the development of much more sophisticated systems for automotive applications. Nevertheless, for the application, which the regulation of the EWB mechanism, it is noted that to achieve the highest level of fidelity protection there is still a significant barrier and downside [19]. Some of the obtained experimental results suggested several delays in the response signal and did not comply with the related theories. Upon analysis, it focuses on the less accurate prediction of the EWB system during the modelling phase, the simplification, idealization, and simulation methodology used during brake system modelling, and yet it is a critical piece of information which determines the brake system 's capabilities. As stated in [20], one of the key factors for achieving desirable control efficiency is the provision of an effective system model that can accurately simulate the system's dynamic behaviour. To date, the EWB framework has two popular methods of dynamic modelling, namely physical modelling (PM) and system identification (SI) methods. These two approaches are very useful in creating a mathematical model for the unit.

However, these methods do have advantages and drawbacks. The SIM technique can generate simulations of the exact responses that are true to the system mechanism [21]. Nonetheless, this model may not be appropriate for other systems. On the other hand, the developed model may be reused for other systems with the same mechanism in the case of PM techniques, but some adjustment of the parameters according to the mechanism of development is needed. In general, based on PM techniques, the dynamic EWB model was derived from the ordinary differential equation (ODE) by dividing the entire EWB system into three subassembly parts: DC-motor, Lead Screw and EWB-Brake Heart [8], [9], [11], [22]. So, these validated models are acceptable, and later contributed to the use of researchers. Even so, in these equations, there are disadvantages where the derivations have not ended with state-space or transfer function, form, and thus make it less reliable to use for control design. The implementation of a full EWB model based on 5 by 5 state space representation [22] surmounted these weaknesses.

It is noted that the EWB mechanism contains nonlinearities and variable parameters in its components which can also affect system performance, such as the efficiency of the lead screw or roller screw and the friction coefficient of the brake pad. The efficiency of the roller and the lead screw will depend on the translational variable, whether it acts as a driver or guide to the rotating part, whereas the pad's coefficient of friction increases proportionally to the pad's surface temperature and decreases the presence of water [23], [24] and water [25]. Otherwise the pad friction also has a nonlinearity of low disk speed which can be expressed with the sigmoid function [23]. Numerous researchers have tried a variety of methods to address these problems. However, the definitive way to solve this problem has yet to be found. In order to contribute to the advancement of the EWB, a complete model of an integrated EWB system using the PM method has been developed in this study. The objectives are deriving mathematical equation for PMDC for EWB, identify the effect of actuation angle, experimentally validate the model, and finally performed performance analysis of the EWB using PID controller.

There are four sections in this article. The first segment focuses on the implementation of the EWB and the review of other relevant work. The complete mathematical modelling of the optimized EWB is then defined, followed by the design section for the required goal, engine selection, and experimental validation of engine and EWB parameters. The PID controller-based clamping force controller is designed to simulate the model and the simulation result is addressed. PID parameters are tuned dependent on optimization-based tuning. Finally, the conclusion and the potential work plan are mixed in the last section.

\section{MATHEMATICAL MODEL OF EWB}

In order to develop the EWB 's suitable mathematical modelling a clear understanding of the EWB process is required to provide better insight. The development of the EWB's mathematical equation is proposed in this section and will be explained on the basis of physical modelling. Subdividing the brake system into several different assemblies is useful for modelling purposes. These can be implemented within the overall model as separate subroutines or blocks, as shown in Figure 1. The brake model is divided into two main parts, the brake actuator, and the heart-brake mechanism. As shown in Figure 1, The brake actuator consisted of two components: the DC motor and the roller screw. The DC motor actuator is used in this system to move the input torque and force the centre brake through a roller screw, which transforms the angular motion of the DC motor into the axial motion of the coil in the centre of the brake. On the other hand, the heart of the brake, consisting of a wedge mechanism, a calliper, and a brake pad, may have diagonal motions, providing a clamping force to the brake disk. 


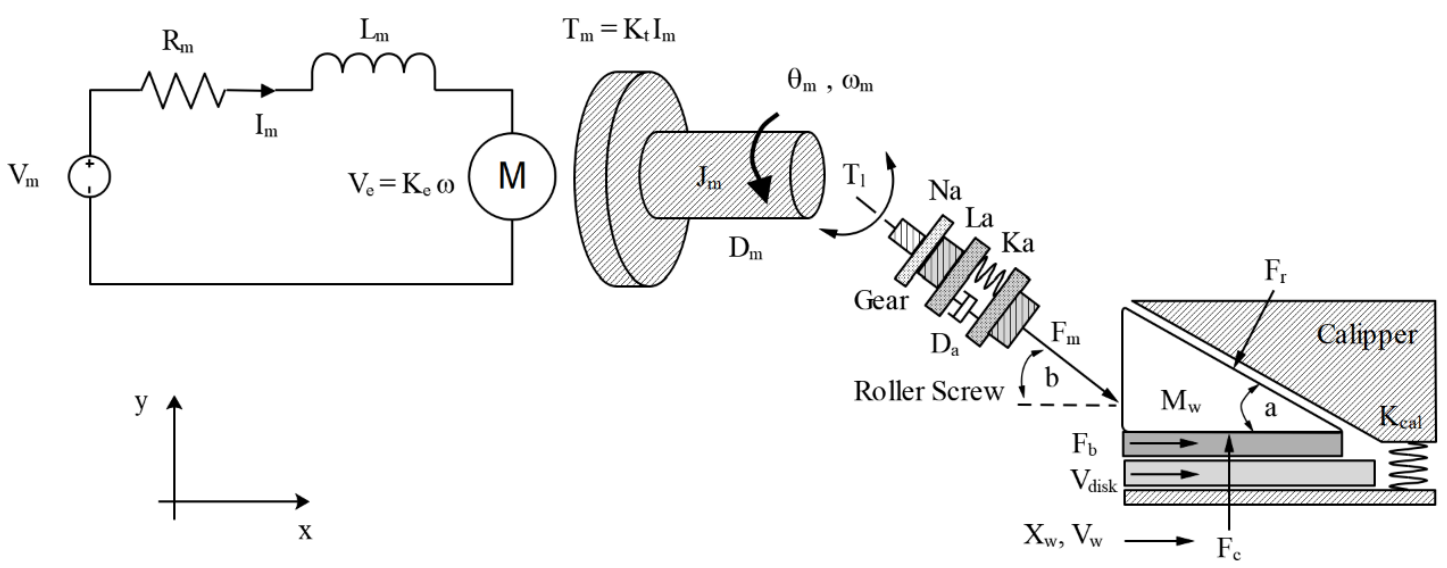

Figure 1. EWB Schematic diagram

\subsection{Brake actuator modelling}

This work used the permanent direct current magnet (PMDC) motor as the actuator. The PMDC motor is basically modelled by considering electrical and mechanical components. Here $\left(J_{m}\right)$ is motor inertia, $\left(K_{t}\right)$ constant torque, $\left(K_{e}\right)$ electromotive force constant, $\left(D_{m}\right)$ viscous friction motor constant and $\left(T_{l}\right)$ load torque. Noted that, the $\left(K_{t}\right)$ is equal to $\left(K_{e}\right)$ if there are no electromagnetic losses in the motor, therefore the electrical power dissipated from the EMF back in the armature is transferred directly to mechanical power.

The mathematical equations of the PMDC motor are shown as follows. For the armature circuits:

$$
\dot{I_{m}}=-\frac{K_{e}}{L_{m}} \omega_{m}-\frac{R_{m}}{L_{m}} I_{m}+\frac{1}{L_{m}} V_{m}
$$

by considering the mechanical load, the rotational acceleration of the DC motor shaft is described as:

$$
\dot{\omega_{m}}=-\frac{D_{m}}{J_{m}} \omega_{m}+\frac{K_{t}}{J_{m}} I_{m}-\frac{1}{J_{m}} T_{l}
$$

here the PMDC motor is connected directly to the brake mechanism using a single lead screw-type start. Afterward, the lead screw accompanied by a lossless planetary reduction gear is attached to the heart mechanism to obtain the required actuation force.

Based on Figure 1, the necessary motor drive force $\left(F_{m}\right)$ can be calculated by taking into account several parameters of the lead screw such as the steadiness of the lead screw, $\left(K_{a}\right)$, the viscous damping of lead screw, $\left(D_{a}\right)$, the reduction of the lead screw gear ratio, $\left(N_{a}\right)$ and the screw lead, $\left(L_{a}\right)$. The lead screw plays an important role in turning the engine angle, $\left(\theta_{m}\right)$, engine speed $\left(\omega_{m}\right)$, and engine torque screw, $\left(T_{\text {screw }}\right)$ into wedge position, $\left(X_{w}\right)$, wedge speed, $\left(V_{w}\right)$, and motor force, $\left(F_{m}\right)$. Remember that when viewed from the motor side, the motor torque screw, $\left(T_{\text {screw }}\right)$ is an engine load, $\left(T_{l}\right)$.

The torque delivered to the screw can be represented as (3), assuming that the planetary reduction gear mass is very light and that the gear mechanism is less frictional. The lead screw output value is between 0 to 1 . This mainly depends on the geometry of the contact surfaces, their finishing, and the helix angle of the lead screw thread. It also depends upon functional conditions such as load, speed, and lubrication. Although a lead screw 's efficiency is a true measured value, objective testing is the best method for determining the results. Based on the experimental work of the researcher the output of the lead screw used varies within certain tolerances from its nominal value [14], [26]. An approximation such as setting a constant value at the efficiency of the screw [27] can also be made, though. The torque / force efficiency of the constant lead screw is set to an optimum value measured at 0.65 for this work.

$$
\begin{aligned}
& T_{\text {screw }}=\frac{N_{a} L_{a}}{2 \pi \eta}\left[K_{a}\left(L_{a} \frac{N_{a} \theta_{m}}{2 \pi}-\frac{X_{w}}{\cos \beta}\right)+D_{a}\left(L_{a} \frac{N_{a} \theta_{m}}{2 \pi}-\frac{V_{w}}{\cos \beta}\right)\right] \\
& F_{m}=2 \pi \eta \frac{T_{\text {screw }}}{N_{a} L_{a}}
\end{aligned}
$$

By substituting (3) into (4), the motor force (Fm) can be defined as follows:

$$
F_{m}=K_{a}\left(L_{a} \frac{N_{a} \theta_{m}}{2 \pi}-\frac{X_{w}}{\cos \beta}\right)+D_{a}\left(L_{a} \frac{N_{a} \theta_{m}}{2 \pi}-\frac{V_{w}}{\cos \beta}\right)
$$




\subsection{Wedge mechanism dynamic}

Consider the EWB with the angle of the motor shaft, $\beta$ as in Figure 1. The relationship between the wedge actuation forces $\left(F_{m}\right)$, reaction forces $\left(F_{r}\right)$, and clamping forces $\left(F_{c}\right)$ to the disc are derived based on force balance as follow:

The dynamic of a wedge in $\mathrm{x}$-direction:

$$
F_{m} \cos \beta+\mu F_{c}-F_{r} \sin \alpha=M_{w} \dot{V}_{w}
$$

By dividing with $\tan \alpha$, the new form of (7) can be described as follow:

$$
F_{r} \cos \alpha=\frac{F_{m} \cos \beta+\mu F_{c}-M_{w} \dot{V_{w}}}{\tan \alpha}
$$

Besides that, the dynamic of a wedge in y-direction stated as:

$$
F_{m} \sin \beta+F_{r} \cos \alpha-F_{c}=M_{w} \dot{V}_{w} \tan \alpha
$$

where $M_{w}$ and $V_{w}$ are wedge mass and wedge velocity in x-direction, respectively. Substitute the (7) into (8), then rearrange will be produced.

$$
\dot{V}_{w}=\frac{F_{n}(\mu-\tan \alpha)}{M_{w}\left(\tan ^{2} \alpha+1\right)}+\frac{F_{m}(\sin \beta \tan \alpha+\cos \beta)}{M_{w}\left(\tan ^{2} \alpha+1\right)}
$$

From (9), we are interested in simplifying the complex multiplier formula of motor force $\left(F_{m}\right)$ which is a function of the motor actuation angle and the wedge angle $\mathrm{f}(\beta, \alpha)$. To achieve optimum multiplication of the brake factor, the motor shaft angle should have the same angle as the wedge angle instead of a zero angle as on a normal EWB. Assuming the two angles are equal, this function can be summarized as follows,

$$
\begin{aligned}
& f(\beta, \alpha)=\cos \beta+\sin \beta \tan \beta \\
& f(\beta, \alpha)=\frac{1}{\cos \beta}
\end{aligned}
$$

Thus, the simplified wedge dynamic model can be described as:

$$
\dot{V}_{w}=\frac{1}{M_{w}\left(\tan ^{2} \alpha+1\right)}\left[F_{c}(\mu-\tan \alpha)+\frac{F_{m}}{\cos \beta}\right]
$$

Meanwhile, the clamping force depends on the calliper stiffness $\left(K_{\text {cal }}\right)$, wedge displacement, and wedge angle.

$$
F_{c}=K_{c a l} X_{w} \tan \alpha
$$

Substitute (11) into (12) then produce,

$$
\dot{V}_{w}=\left[\frac{K_{c a l} \tan \alpha(\mu-\tan \alpha)}{M_{w}\left(\tan ^{2} \alpha+1\right)}\right] X_{w}+\left[\frac{1}{M_{w}\left(\tan ^{2} \alpha+1\right) \cos \beta}\right] F_{m}
$$

Where:

$$
\beta= \begin{cases}0 & , \text { for Normal EWB } \\ \alpha & , \text { for Optimized EWB }\end{cases}
$$

\subsection{Wedge brake factor}

The EWB braking factor plays an important role in enlarging the ratio of braking force versus actuator force. In contrast to the conventional braking factor, the wedge-based brake system will increase several times the braking factor due to the self-energizing effect. In steady state condition, in (10) can be simplified as follows: 


$$
F_{c}(\mu-\tan \alpha)+\frac{F_{m}}{\cos \beta}=0
$$

a pair of brake pads installed each wheel disk generate double brake force. Thus, relation between braking forces and clamping forces is stated as,

$$
F_{c}=\frac{F_{b}}{2 \mu}
$$

Substituting (14) to (13), and then rearranging the equation will produce a wedge characteristic brake factor, $\mathrm{C} *$

$$
C^{*}=\frac{F_{b}}{F_{m}}=\frac{2 \mu}{\tan \alpha-\mu}\left(\frac{1}{\cos \beta}\right)
$$

where:

$$
\beta= \begin{cases}0 & , \text { for Normal EWB } \\ \alpha & , \text { for Optimized EWB }\end{cases}
$$

Based on (15), we can realize that although the actuator angle $(\beta)$ should be set equal to the wedge angle $(\alpha)$ to obtain optimum amplification of the braking factor, the amount of additional amplification in the EWB varies according to the angle of the actuator. The additional amplification value increase as angle of wedge increase. Furthermore, the efficiency of the personalized EWB can be calculated using (15). By using the recommended wedge angle spacing for standard coefficient of friction brake pads, which is approximately 25 to 43 degrees [28], the optimized EWB increases the braking factor from 10.3 to 36.7 percent compared to the normal EWB. As shown in Table 1, the (15) developed to represent the characteristic brake factor is simpler and slightly differs from other researchers. Many researchers multiply the equation by two, as each wheel uses a double brake pad. The researchers still underestimate the wedge friction coefficient $\left(\mu_{\mathrm{w}}\right)$ but are considered in [28].

Table 1. Brake factor formula representation by researchers

\begin{tabular}{lc}
\hline \multicolumn{1}{c}{ Source } & Equation of characteristic brake factor of optimized EWB \\
\hline Year 2007, Fox et al. [8], & $\frac{2 \mu}{\tan \alpha-\mu}(\cos \beta+\sin \beta \tan \alpha)$ \\
Year 2013, Park et al. [29] & $\frac{\mu}{\tan \alpha-\mu} \times \frac{\cos (\alpha-\beta)}{\cos \alpha}$ \\
Year 2015, Shin et al. [13] & $\frac{2 \mu}{\cos \alpha(\tan \alpha-\mu)+\mu_{w} \cos \alpha+\mu_{w} \mu \sin \alpha}$ \\
Year 2017, Wang et al. [28] & $\frac{2 \mu}{\tan \alpha-\mu}\left(\frac{1}{\cos \beta}\right)$ \\
This article &
\end{tabular}

\subsection{Proposed complete EWB model}

The entire EWB model can be obtained by combining all the mathematical differential equations, as discussed previously in a separate component. There are 5 states available, which are wedge distance $\left(X_{w}\right)$, wedge velocity $\left(V_{w}\right)$, motor angle $\left(\theta_{m}\right)$, angular motor velocity $\left(\omega_{m}\right)$, and motor current $\left(I_{m}\right)$. Substitute $(5)$ for the dynamic wedge from the axial lead screw to (12).

$$
\begin{gathered}
\dot{V}_{w}=\left[\frac{K_{\text {cal }} \tan \alpha(\mu-\tan \alpha)-K_{a} / \cos ^{2} \beta}{M_{w}\left(\tan ^{2} \alpha+1\right)}\right] X_{w}+\left[-\frac{D_{a}}{M_{w}\left(\tan ^{2} \alpha+1\right) \cos ^{2} \beta}\right] V_{w}+\left[\frac{K_{a} L_{a} N_{a} / 2 \pi}{M_{w}\left(\tan ^{2} \alpha+1\right) \cos \beta}\right] \theta_{m} \\
+\left[\frac{D_{a} L_{a} N_{a} / 2 \pi}{M_{w}\left(\tan ^{2} \alpha+1\right) \cos \beta}\right] \dot{\theta_{m}}
\end{gathered}
$$

By substitute (3) for lead screw into (2) from PMDC Motor mechanical equation, then rearrange it as,

$$
\dot{\omega_{m}}=\left[\frac{L_{a} N_{a} K_{a}}{2 \pi \eta J_{m} \cos \beta}\right] X_{w}+\left[\frac{L_{a} N_{a} D_{a}}{2 \pi \eta J_{m} \cos \beta}\right] V_{w}+\left[-\frac{\left(L_{a} N_{a}\right)^{2} K_{a}}{4 \pi^{2} \eta J_{m}}\right] \theta_{m}+\left[-\frac{\left(L_{a} N_{a}\right)^{2} D_{a}}{4 \pi^{2} \eta J_{m}}-\frac{D_{m}}{J_{m}}\right] \omega_{m}+\left[\frac{K_{t}}{J_{m}}\right] I_{m}
$$


The (1) from PMDC Motor electrical equation can be rearranged as follow,

$$
\dot{I}_{m}^{\cdot}=\left[-\frac{K_{e}}{L_{m}}\right] \omega_{m}+\left[-\frac{R_{m}}{L_{m}}\right] I_{m}+\left[\frac{1}{L_{m}}\right] V_{m}
$$

The complete EWB actuator model representing the combination of the engine, the lead screw with the gear and the EWB (brake heart) mechanism is finally derived from this. Final differential (16), (17) and (18) may be depicted for the form in the fifth-order linear state space:

$$
\begin{aligned}
& \left\{\begin{array}{l}
\dot{X}=A x+B u \\
y=C x+D u
\end{array}\right. \\
& x=\left[X_{w}, V_{w}, \theta_{m}, \omega_{m}, I_{m}\right]^{T} \\
& y=F_{c}
\end{aligned}
$$

$A=\left[\begin{array}{ccccc}0 & 1 & 0 & 0 & 0 \\ \frac{-K_{a}-a_{1} a_{4}{ }^{2}}{a_{2} a_{4}{ }^{2}} & \frac{-D_{a}}{a_{2} a_{4}{ }^{2}} & \frac{K_{a} a_{3}}{a_{2} a_{4}} & \frac{D_{a} a_{3}}{a_{2} a_{4}} & 0 \\ 0 & 0 & 0 & 1 & 0 \\ \frac{K_{a} a_{3}}{\eta J_{m} a_{4}} & \frac{D_{a} a_{3}}{\eta J_{m} a_{4}} & \frac{-K_{a} a_{3}{ }^{2}}{\eta J_{m}} & \frac{-D_{m}}{J_{m}}-\frac{D_{a} a_{3}{ }^{2}}{\eta J_{m}} & \frac{K_{t}}{J_{m}} \\ 0 & 0 & 0 & \frac{-K_{e}}{L_{m}} & \frac{-R_{m}}{L_{m}}\end{array}\right], B=\left[\begin{array}{c}0 \\ 0 \\ 0 \\ 0 \\ \frac{1}{L_{m}}\end{array}\right], \quad$ and $C=\left[\begin{array}{c}K_{\text {cal }} \tan (\alpha) \\ 0 \\ 0 \\ 0 \\ 0\end{array}\right]^{T}$

where

$a_{1}=K_{c a l} \tan \alpha(\tan \alpha-\mu)$

$a_{2}=M_{w}\left(\tan ^{2} \alpha+1\right)$

$a_{3}=\frac{L_{a} N_{a}}{2 \pi}$

$a_{4}=\cos \beta$,

$\beta= \begin{cases}0 & , \text { for Normal Actuation EWB } \\ \alpha & , \text { for Optimized Actuation EWB }\end{cases}$

\section{MODEL VALIDATION}

\subsection{Brake requirement}

Several specifications were laid out in this study to define the optimum braking force in the design of the EWB. The objective is to develop an EWB system for the use of medium sized passenger vehicles in the Bsegment as in [30]. The effective braking force generated by the electronic wedge brake depends primarily on the angle of the wedge. Determination of the optimum wedge angle is therefore critical in the design of the electronic wedge brake. Since the angle of the wedge depends on the coefficient of friction of the brake pad, priority should be given to selecting the brake pad. The angle of the wedge and the selection of the brake pad are two critical factors to produce a higher braking force and to avoid the possibility of the wedge sticking. Therefore, in this study, a brake pad type FF (SAE Code) with a friction coefficient ranging from 0.35 to 0.45 was selected for use in the design of the EWB. Based on the coefficient of the brake pad, the optimization was performed and the optimum wedge for the wedge function was found to be 24.5 degrees.

By substituting the wedge angle and the pad coefficient value for (15), the brake factor of the selected wedge angle may be tested. A brake factor of around 7.276 can be produced with a pad coefficient of 0.35 . If $\beta$ is not entered in the equation (normal EWB) only 6.621 will be produced for the same parameter otherwise. Self-reinforcement at the maximum value will be at a friction coefficient of 0.45 , so no motor force is required. When the pad coefficient exceeds this value, however, it is very difficult to control, because the brake factor is very high. In addition, it is checked using the same equation that only $982.96 \mathrm{~N}$ motor power is required to produce a maximum braking force of $7152 \mathrm{~N}$.

In addition, the necessary engine torque can be examined by consuming (4). Here, it is set that La is 3 $\mathrm{mm}$, that $\eta$ is 0.65 , and that $\mathrm{Na}$ is 1 . Noted, the Fm. It is equivalent to $982.96 \mathrm{~N}$, which has already been calculated. The torque generated by this measurement is $0.7220 \mathrm{Nm}$. Otherwise, (20) can be used to obtain the required engine speed. This equation assumes that the load generated by the wedge movement is linear.

$$
R P M_{\text {target }}=\frac{60 * G_{w}}{L_{a} \tau \tan \alpha}
$$


The equation as the $G_{w}$ is a wedge travelling distance at the average braking force from the rest position to the maximum displacement, which is the goal time to reach. The distance between the pad and the disk is set at $0.5 \mathrm{~mm}$ (gapping mode), and the maximum displacement during brake operation is $0.5 \mathrm{~mm}$ (clamping mode). The target time for achieving maximum brake force is set at $0.2 \mathrm{~s}$. The maximum engine speed achieved by the target RPM is 219.43 RPM, based on these parameters.

Engine selection was made by reference to the parameters calculated. It is determined that Xiangyi Enterprise Co., Ltd 's DC carbon-brush engine model IG-420024X with a rated torque of 0.98 NM at 248 RPM is suitable for design requirements. Noted the engine had a power rating at $41.3 \mathrm{~W}$ and can vary according to torque and set rpm. This choice of engine is rational since about $60 \mathrm{~W}$ of input power is currently used in [27] to stop the vehicle at demand of $950 \mathrm{Nm}$, while another researcher is using less than $50 \mathrm{~W}$ to stop $2000 \mathrm{~kg}$ of the vehicle [7].

\subsection{Controller design}

The EWB controller is performed to verify system performance based on the requirement of target design and to ensure the efficiency of the previous motor selection procedure. Using the MATLAB control system designer tool, the proportional-integral-derivative (PID) tuned gradient-descent-active-set algorithm optimisation method. The proper tuning based on SISO-Optimization technique [31], [32] is used to reduce response time to the minimum level.

The optimization is performed based on a design requirement depending on an overshoot of 5 per cent, an increase of $0.2 \mathrm{~s}$, and an actuator saturation limit of $0.0012 \mathrm{~V}$ for the reference unit step. The PMDC engine used receives an input voltage of up to $12 \mathrm{~V}$, and the maximum braking force at each front wheel is $7.152 \mathrm{~N}$. Thus, the maximum clamping force required by dividing it with the brake pad coefficient is 10,217 $\mathrm{N}$. The actuator saturation shall be considered to sustain the brake force controller output from the minimum to the maximum braking force requirements for a wide working envelope.

Due to the existing constraint rule solution set during optimisation, the design criterion was readjusted at an optimum level. Based on this analysis, the parameters of the PID controller, which is the proportional gain, $K_{P}$, are obtained. It is 0.000289 , integral gain, $K_{I}$. It is 0.000606 . The derivative gain, $K_{D}$. It is $2.97 \times 10-5$, and the time constant of the derivative first-order filter, $T_{f}$. It is 0.0325 .

\section{EXPERIMENTAL VALIDATION AND EWB PARAMETERS}

Since all 6 DC motor parameters are not directly informed, the engine performance during no-load and the average load available on the datasheet are used as a guide to the engine parameters obtained. However, by solving motor mathematical modelling on (1) and (2) with datasheet information, only 4 parameters can be obtained. Using the MATLAB software, two other parameters are obtained, engine inertia and inductance, by evaluating the physical motor via system identification. The engine encoder's motor location signal is connected to the PC via the NI-PCI-6221 DAQ card. To obtain two additional motor parameters, the approximate transfer function model obtained is then replaced with another 4 available parameters. Based on these parameters the engine characteristics graph is produced to be validated with the engine data sheet as in Figure 2.

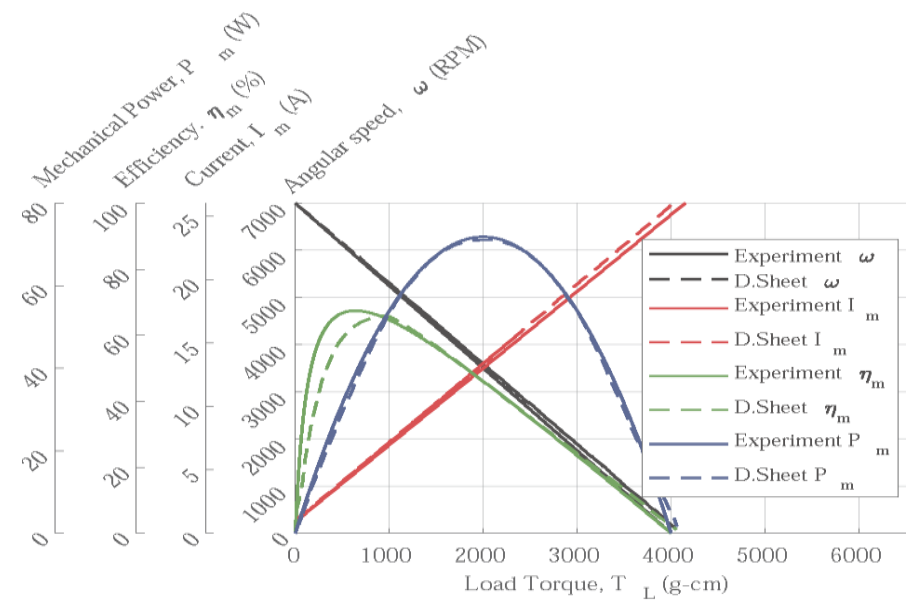

Figure 2. PMDC motor characteristics based on experimental data and IG-420024X graph datasheet 
As illustrated in Figure 2. The parameters obtained in the previous method are true because the trend and the value of the graph obtained are identical to the trend shown in the datasheet of the supplier. Several parameters are obtained to test the complete EWB model, based on physical parameters such as selected DC motor, brake pad, and wedge parameters, and others taken from research papers as mentioned in the previous discussion. Because the EWB prototype still under production, those specifications have not yet been finalized. Table 2 lists all parameters used for this research.

Table 2. EWB DC carbon-brush motor model IG-420024X parameters

\begin{tabular}{cll}
\hline No & \multicolumn{1}{c}{ Parameter, Symbol } & \multicolumn{1}{c}{ Value (Unit) } \\
\hline 1 & Motor Resistance, $R_{m}$ & $0.4781 \Omega$ \\
2 & Motor Inductance, $L_{m}$ & $0.0230 \mathrm{H}$ \\
3 & Electromotive Force Constant, $K_{e}$ & $0.0158 \mathrm{~N} . \mathrm{m} / \mathrm{A}$ \\
4 & Torque constant, $K_{t}$ & $0.0156 \mathrm{~N} . \mathrm{m} / \mathrm{A}$ \\
5 & Motor moment inertia, $J_{m}$ & $7.094 \times 10-3 \mathrm{Kg} . \mathrm{m} 2 / \mathrm{s} 2$ \\
6 & Motor viscous friction constant, $D_{m}$ & $1.9175 \times 10-5 \mathrm{~N} . \mathrm{m} . \mathrm{s}$ \\
7 & Gear Reduction, $N_{a}$ & $1 / 24$ \\
8 & Axial stiffness, $K_{a}$ & $750 \mathrm{e} 6 \mathrm{~N} / \mathrm{m}$ \\
9 & Axial viscous friction constant, $D_{a}$ & $9.3279 \times 10-5$ \\
10 & Lead Screw efficiency, $\eta$ & 0.63 \\
11 & Lead Screw Pitch, $L_{a}$ & $3 \mathrm{~mm}$ \\
12 & Wedge Weight, $M_{w}$ & $0.3 \mathrm{Kg}$ \\
13 & Wedge Angle, $\alpha$ & $24.5 \mathrm{degree}$ \\
14 & Motor axial angle, $\beta$ & $24.5 \mathrm{degree}$ \\
15 & Calliper stiffness, $K_{c a l}$ & $44.8385 \times 106 \mathrm{~N} / \mathrm{m}$ \\
16 & Brake pad coefficient, $\mu$ & 0.35 \\
\hline
\end{tabular}

\section{RESULTS AND DISCUSSION}

This stage is designed to ensure engine selection and other EWB parameters follow design requirements. For this reason, the brake clamping force control system is designed. A series of tests were performed to investigate the performance of the system for the entire operating envelope, i.e., from low to maximum brake clamping force as shown in Figure 3. It shows that the designed controller met the performance requirements for a series of step commands. The main key to consistency in performance is due to the saturation of the actuator consideration during system design.

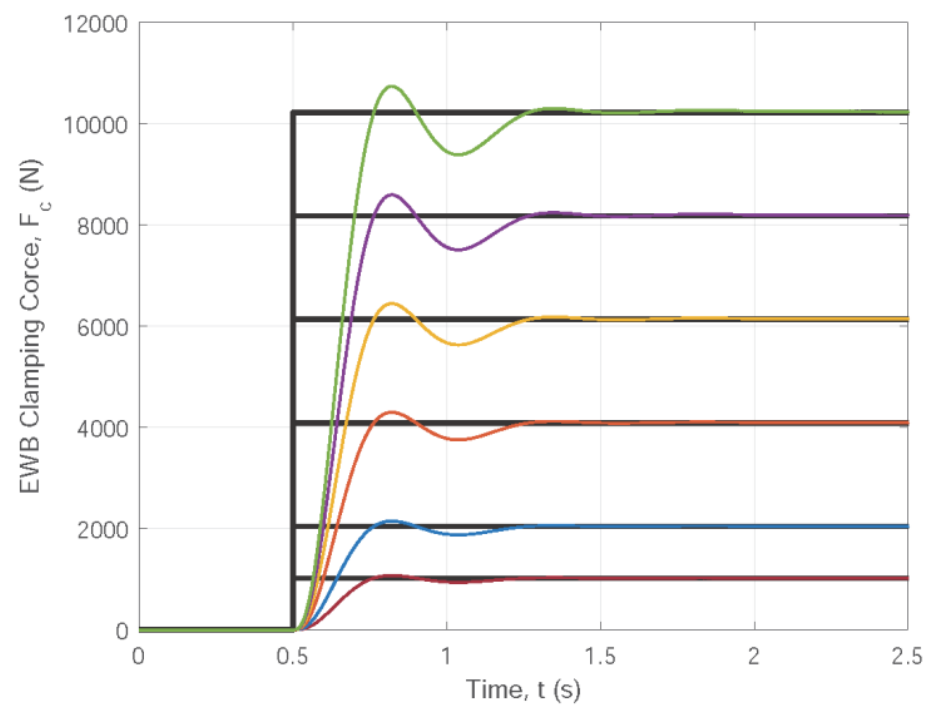

Figure 3. PID based EWB brake clamping force response to force step commands of 10\%, 20\%, 40\%, 60\%, $80 \%$ and $100 \%$ from maximum $10,217 \mathrm{~N}$ force demand

The investigation of designed system behaviour is further evaluated during step input tracking with maximum clamping force of 10,217 $\mathrm{N}$ as in Figure 4. 
As in Figure 4(a), at maximum force demand, the overshoot, rise time and settling time were 5.08 per cent, 0.16 seconds, and 0.70 seconds, respectively, with zero steady state error. Meanwhile the controller working within actuator limit as shown in Figure 4(a) at second axes. The controller output achieves the design specification goal set. It has demonstrated the effectiveness of the engine selection method used earlier. Figure 4(b) shows that the wedge position at a maximum displacement of $0.5 \mathrm{~mm}$ at the maximum brake clamping force and the small bit vibration occurs at the wedge before the wedge is settled. The engine angular velocity peak value is also $160.9 \mathrm{rad} / \mathrm{s}$, which is far from a maximum engine speed of $733 \mathrm{rad} / \mathrm{s}$. Furthermore, another 3 states of the EWB model that represent PMDC motor behaviour during closed-loop for maximum braking demand are observed and shown in Figure 5.

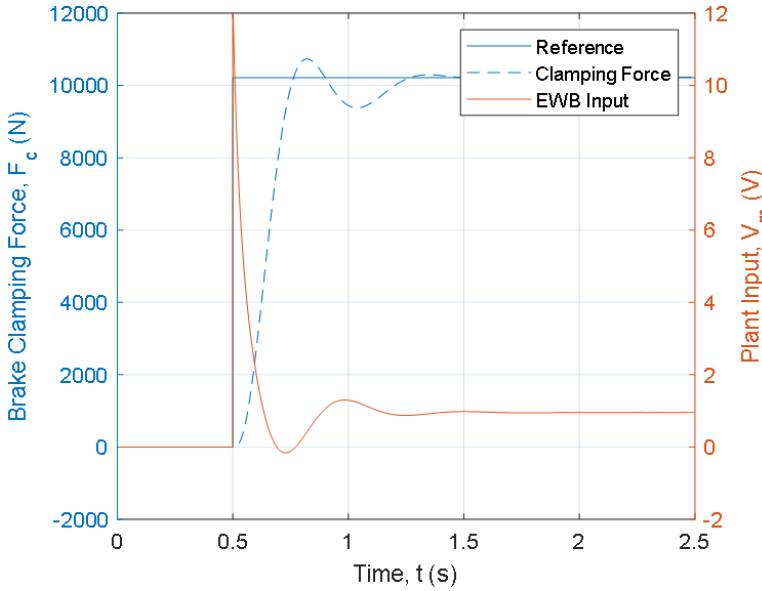

(a)

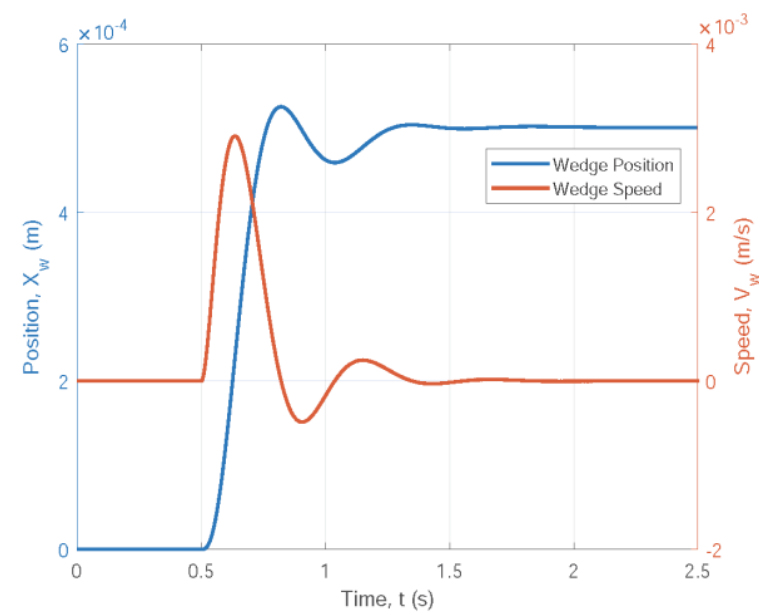

(b)

Figure 4. System behaviour at maximum demand; (a) clamping force and actuator effort and (b) wedge position and speed states responses

As Figure 5(a), the wedge and motor reaction are almost a similar pattern for both position and speed and can be further investigated. The actuator current present is $9.5 \mathrm{~A}$, as in Figure 5(b) just below the engine level. Note that this simulation does not include travel time from the brake pad resting state until the pad and disc meet each other.

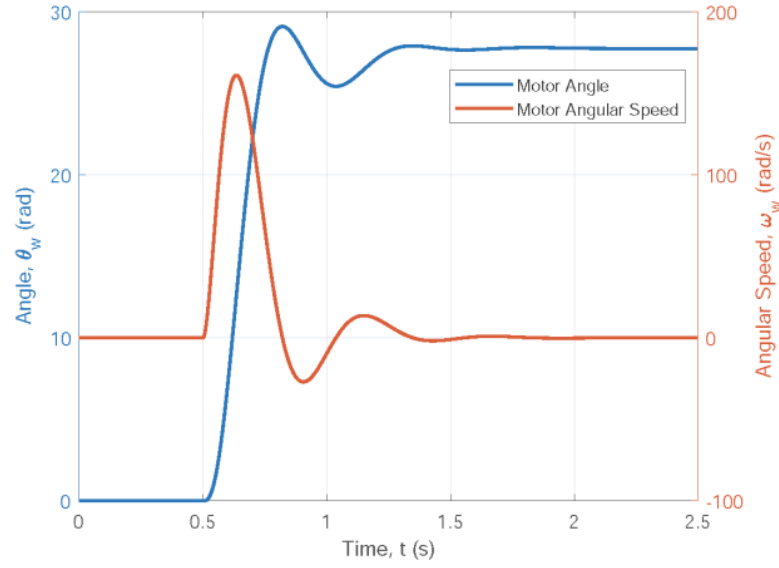

(a)

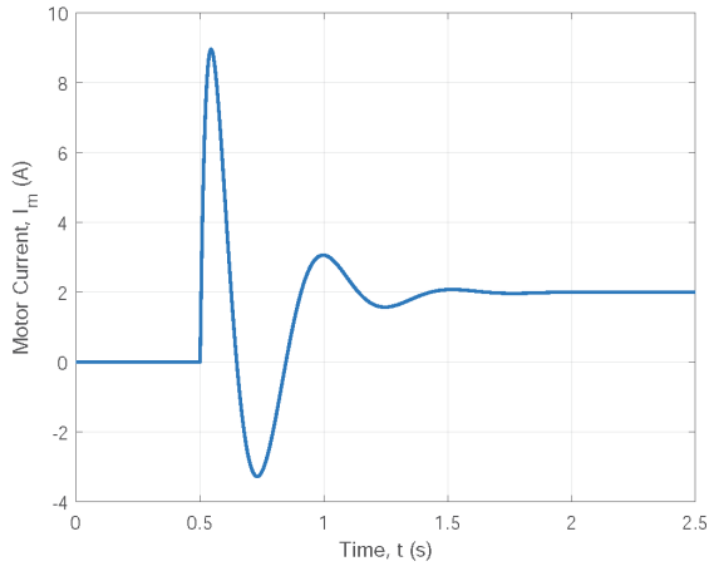

(b)

Figure 5. PMDC motor behaviour at maximum demand; (a) Motor angle and angular speed states responses and (b) motor current state response 


\section{CONCLUSION}

The mathematical equations for the complete EWB model have been produced and optimized. The model is more compact and simpler compared to the various versions of EWB that researchers have used before. Moreover, it is very flexible so that it can be applied to both well-known designs which are activated and optimized activation versions. The activation angle effect is identified where the EWB brake factor can reach up to 36.7 per cent depending on the selection of the brake pads and wedge angle design. The PMDC drive model used in producing an EWB has been experimentally validated with results that are very similar to the performance datasheets from the manufacturer. Performance analysis for the designed EWB was performed using a PID controller. The results show that the designed model can perform very well in accordance with the requirements of the system.

\section{ACKNOWLEDGEMENTS}

The authors would like to thank Universiti Teknikal Malaysia Melaka (UTeM) for the Short Term Research University Grant PJP/2020/FKM/PP/S01783, and the Faculty of Engineering, Universiti Putra Malaysia (UPM) for providing the facilities and conducive learning environment in conducting the research.

\section{REFERENCES}

[1] Hartmann, H., Schautt, M., Pascucci, A., and Gombert, B., "eBrake ${ }^{\circledR}$ - The Mechatronic Wedge Brake," SAE Technical Paper, pp. 2146-2151, 2002, doi: 10.4271/2002-01-2582.

[2] Roberts, R., Gombert, B., Hartmann, H., Lange, D., and Schautt, M. "Testing the mechatronic wedge brake," SAE Technical Paper, vol. 1, no. 724, 2004. doi: 10.4271/2004-01-2766.

[3] Ho, L. M., Roberts, R., Hartmann, H., and Gombert, B., "The Electronic Wedge Brake - EWB," SAE Technical Paper, no. 2006-01-3196, 2006, doi: 10.4271/2006-01-3196.

[4] Kim, J. G., Kim, M. J., Kim, J. K., and Noh, K. H., "Developing of Electronic Wedge Brake with Cross Wedge," SAE Technical Paper, no. 2009-01-0856, 2009, doi: 10.4271/2009-01-0856.

[5] Ghajari, A. and Kazemi, R., "A New Approach to the Electronic Wedge Brake," SAE Technical Paper, no. 201201-1801, 2012, doi: 10.4271/2012-01-1801.

[6] Abd. Rahman, M. L. H., Hudha, K., Ahmad, F., and Jamaluddin, H., "Design and clamping force modelling of electronic wedge brake system for automotive application," International Journal of Vehicle Systems Modelling and Testing, vol. 8, no. 2, pp. 145-156, 2013, doi: 10.1504/IJVSMT.2013.054478.

[7] Semsey, Á. and Roberts, R., "Simulation in the Development of the Electronic Wedge Brake," SAE Technical Paper, no. 2006-01-0298, 2006, doi: 10.4271/2006-01-0298.

[8] Fox, J., Roberts, R., Baier-Welt, C., Ho, L. M., Lacraru, L., and Gombert, B., "Modeling and Control of a Single Motor Electronic Wedge Brake," SAE Technical Paper, no. 2007-01-0866, 2007, doi: 10.4271/2007-01-0866.

[9] Emam, M. A. A., Emam, A. S., El-Demerdash, S. M., M. Shaban, and S., Mahmoud, M. A., "Performance of Automotive Self Reinforcement Brake System," Journal of Mechanical Engineering, vol. 1, no. 1, pp. 4-10, 2012.

[10] Cheon, J., "Single Motor Electronic Wedge Brake System Locking Parking Force," U. S. Patent DE 102007053 922 A1, Apr. 02, 2012.

[11] Jo, C.-H., Lee, S.-M., Song, H.-L., Cho, Y.-S., Kim, I., Hyun, D.-Y., and Kim, H.-S., "Design and control of an upper-wedge-type electronic brake," Proceedings of the Institution of Mechanical Engineers, Part D: Journal of Automobile Engineering, vol. 224, no. 11, 2010, pp. 1393-1405, doi: 10.1243/09544070JAUTO1268.

[12] Yu, L., Chang, J., and Zheng, S., "Proof-of-Concept Design of Electronic Wedge Brake with Multi-Rollers," Proceedings of the ASME 2017 International Design Engineering Technical Conferences and Computers and Information in Engineering Conference IDETC/CIE 2017, American Society of Mechanical Engineers, Ohio, 2017, doi: 10.1115/DETC2017-68103.

[13] Shin, D. H., Lee, S., Jeong, C. P., Kwon, O. S., Park, T. S., Jin, S. H., Ban, D. H., and Yang, S. H, "Analytic approaches for keeping high braking efficiency and clamping efficiency of electro wedge brakes," International Journal of Precision Engineering and Manufacturing, vol. 16, no. 7, pp. 1609-1615, 2015, doi: 10.1007/s12541-015-0211-1.

[14] Han, K., Huh, K., Chun, J., Kim, M., and Kim, J., "Design Of Hardware Architecture And Control Algorithm For The Electronic Wedge Brake," Proceedings of the ASME 2010 Dynamic Systems and Control Conference DSCC2010, ASME, Cambridge, Massachusetts, USA, 2010, pp. 1-6, doi: 10.1115/DSCC2010-4115.

[15] Cheon, J. S., "Brake By Wire System Configuration and Functions using Front EWB (Electric Wedge Brake) and Rear EMB (Electro-Mechanical Brake) Actuators," SAE Technical Paper, no. 2010-01-1708. 2010, doi: 10.4271/2010-01-1708.

[16] Gombert, B. D. M., Schautt, M., and Roberts, R. P., "The Development of Alternative Brake Systems," Encyclopedia of Automotive Engineering, Chichester, UK: John Wiley \& Sons, Ltd, pp. 1-11, 2014, doi: 10.1002/9781118354179.auto025.

[17] Shin, D. H. and An, J. N., "Study of Stiffness Design of Caliper for Reducing the Weight of an Electro Wedge Brake," Applied Mechanics and Materials, vol. 138-139, pp. 159-162, 2011, doi: 10.4028/www.scientific.net/AMM.138-139.159.

[18] Said Jneid, M. and Joukhadar, A., "LQR-Based Control of a Single Motor Electronic Wedge Brake EWB for Automotive Brake-By-Wire System," Soft Computing and Electrical Engineering, vol. 1, no. 1, pp. 12-35, 2019. 
[19] Ahmad, F., Hudha, K., Mazlan, S. A., Jamaluddin, H., Aparow, V. R., and Yunos, M. M., "Simulation and experimental investigation of vehicle braking system employing a fixed caliper based electronic wedge brake," Simulation, vol. 94, no. 4, pp. 327-340, 2018, doi: 10.1177/0037549717733805.

[20] Ahmad, F., Hudha, K., Mazlan, S. A., Jamaluddin, H., Zamzuri, H., Kadir, Z. A., and Aparow, V. R., "Modelling and control of a fixed calliper-based electronic wedge brake," Journal of Mechanical Engineering, vol. 63, no. 3, pp. 181-190, 2017, doi: 10.5545/sv-jme.2016.3508.

[21] Schoukens, J. and Pintelon, R., "Identification of Linear Systems : A Practical Guideline to Accurate Modeling (1st ed.)," Pergamon Press, Britain, 2014.

[22] Hwang, Y. and Choi, S. B., "Robust control of electronic wedge brake with adaptive pad friction estimation," International Journal of Vehicle Design, vol. 62, no. 2/3/4, p. 165, 2013, doi: 10.1504/IJVD.2013.052709.

[23] Balogh, L., Stréli, T., Németh, H., and Palkovics, L., "Modelling and simulating of self-energizing brake system," Vehicle System Dynamics, vol. 44, no. sup1, pp. 368-377, 2006, doi: 10.1080/00423110600872267.

[24] Ghazaly, N. M., "A Preliminary Experimental Investigation of a New Wedge Disc Brake," International Journal of Engineering Research and Applications, vol. 3, no. 6, pp. 735-744, 2013.

[25] Ghazaly, N. M., Makrahy, M. M., Gwwad, K. A. A. E., Mahmoud, K. R., and Tawwab, A. M. A. E., "Experimental Evaluation of an Empirical Model for Wedge Disc Brake using Box-Behnken Design," International Journal of Vehicle Structures and Systems, vol. 6, no. 3, pp. 58-63, 2014, doi: 10.4273/ijvss.6.3.03.

[26] Han, K.; Huh, K., and Kim, M. "Modeling and control of an electronic wedge brake," Proceedings of the Institution of Mechanical Engineers, Part C: Journal of Mechanical Engineering Science, vol. 226, no. 10, 2012, pp. 2440-2455, doi: 10.1177/0954406211435584.

[27] Roberts, R., Schautt, M., Hartmann, H., and Gombert, B., "Modelling and Validation of the Mechatronic Wedge Brake," SAE International, no. 724, 2003, doi: 10.4271/2003-01-3331.

[28] Wang, J., Zhang, Y., Yang, N., Song, D., and Wang, Q., "Parameters design and braking efficiency analysis of a hydraulic self-energizing wedge disc brake," International Journal of Precision Engineering and Manufacturing, vol. 18, no. 10, pp. 1409-1418, 2017, doi: 10.1007/s12541-017-0168-3.

[29] Park, H. and Choi, S. B. "Development of a Sensorless Control Method for a Self-Energizing Brake System Using Noncircular Gears," IEEE Transactions on Control Systems Technology, vol. 21, no. 4, pp. 1328-1339, 2013, doi: 10.1109/TCST.2012.2204750.

[30] Che Hasan, M. H., Khair Hassan, M., Ahmad, F., and Marhaban, M. H., "Modelling and Design of Optimized Electronic Wedge Brake," 2019 IEEE International Conference on Automatic Control and Intelligent Systems (I2CACIS), IEEE, Shah Alam, 2019, pp. 189-193, doi: 10.1109/I2CACIS.2019.8825045.

[31] Alkhafaji, F. S. M., Wan Hasan, W. Z., Isa, M. M., and Sulaiman, N., "A response time reduction for DC motor controller using SISO technique," Indonesian Journal of Electrical Engineering and Computer Science, vol. 17, no. 2, pp. 895-906, 2019, doi: 10.11591/ijeecs.v17.i2.pp895-906.

[32] Sultan, G. A. and Jarjes, M. K., "Optimal PID controller design using artificial bee colony algorithm for robot arm," Indonesian Journal of Electrical Engineering and Computer Science, vol. 21, no. 1, pp. 84-91, 2021, doi: 10.11591/ijeecs.v21.i1.pp84-91.

\section{BIOGRAPHIES OF AUTHORS}

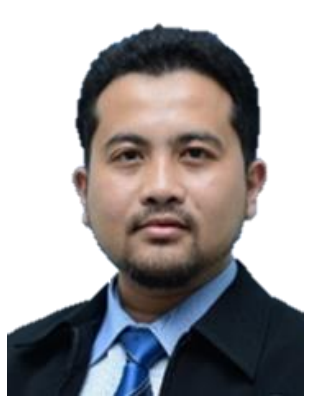

Mohd Hanif Che Hasan was born in Kelantan, Malaysia. He received the B.Eng. degree in electrical engineering (mechatronic) from the Universiti Teknologi Malaysia (UTM), Skudai, Johor, Malaysia in 2003, and the M.Eng. degree in electrical - mechatronics and automatic control from the same university in 2013. He is currently pursuing the Ph.D. degree in control system engineering at the Universiti Putra Malaysia (UPM), Serdang, Selangor, Malaysia. From 2003 to 2007, he was an engineer with the Mitsubishi Electric (M) Sdn. Bhd. Since 2007, he joins Universiti Teknikal Malaysia Melaka (UTeM), Malaysia as academic staff. His current research interests include applied control system, image processing, SCADA, computer-based system, microcontroller, and PLC based application.

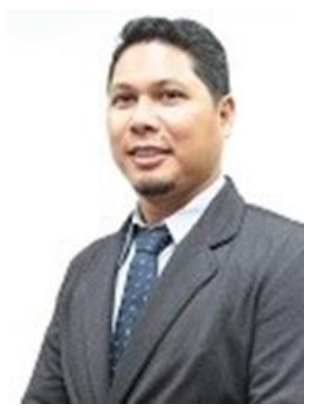

Mohd. Khair Hassan was born in Malacca, Malaysia. He received the B.Eng. degree in electrical and electronic engineering from the University of Portsmouth, U.K., in 1998, the M.Eng. degree in electrical engineering from Universiti Teknologi Malaysia (UTM), Skudai, Johor, Malaysia, in 2001, and the Ph.D. degree in automotive from Universiti Putra Malaysia (UPM), Serdang, Selangor, Malaysia, in 2011. He is currently an Associate Professor with the Department of Electrical and Electronic Engineering, UPM. His area of interests includes control system, automotive control, electric vehicle, and AI applications. Currently, his focuses are on x-by-wire technology and optimal strategy for energy consumption in electric vehicle. Dr. M.K. Hassan is a Professional Engineer registered under Board of Engineers Malaysia, a Corporate Member of the Institution of Engineers Malaysia, and a member of the Society of Automotive Engineers 


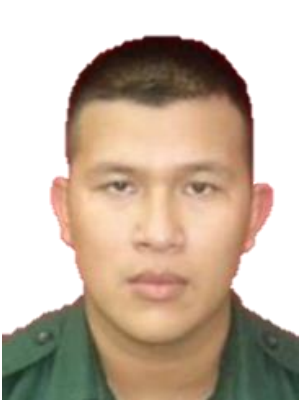

Fauzi Ahmad received the B.Eng. degree in mechanical engineering from Universiti Teknikal Malaysia Melaka, Malaysia (UTeM), in 2007, the M.Sc. degree in mechanical engineering (automotive) from same university in 2010, and the Ph.D. degree in automotive from Universiti Teknologi Malaysia (UTM) - MJIT, Semarak, Kuala Lumpur, Malaysia, in 2017. $\mathrm{He}$ is currently a Senior Lecturer with the Faculty of Mechanical Engineering, UTeM. His research interests include tire modelling, vehicle ride and handling and pneumatic system modelling and control.

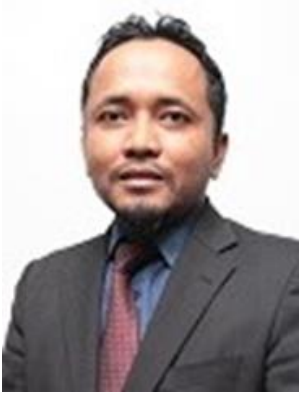

Mohammad Hamiruce Marhaban received the B.Eng. in Electrical and Electronics Engineering from the University of Salford in 2003. He then obtained his doctorate, $\mathrm{PhD}$ in Electrical and Electronics Engineering, from the University of Surrey in 2003. His outstanding achievements in research, publications, supervision, and consultancy led to his appointment as a Professor of UPM in 2015. Currently, he is the Director of the Research Management Centre of UPM. His research interests include Artificial Intelligence, Computer Vision and Robotics.

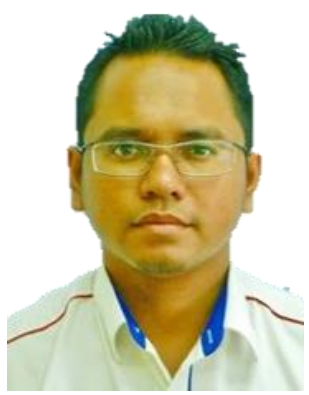

Sharil Izwan Haris received the B.Eng. degree in mechanical engineering from Universiti Teknologi Malaysia (UTM), Skudai, Johor, Malaysia in 2003, and the M.Sc. degree in mechanical engineering from Universiti Teknikal Malaysia Melaka, Malaysia (UTeM), in 2016. He is currently pursuing the Ph.D. degree in automotive engineering at Universiti Teknikal Malaysia Melaka, Malaysia (UTeM), Melaka, Malaysia. 